\title{
EXPERIMENTAL AND ANALYTICAL COMPARISON OF TORSION, BENDING MOMENT AND SHEAR FORCES IN REINFORCED CONCRETE BEAMS USING BS 8110, EURO CODE 2 AND ACI 318 PROVISIONS
}

\author{
C. P. Amulu ${ }^{1, *}$ and C. A. Ezeagu ${ }^{2}$ \\ 1, 2 Department of Civil EngineEring, NnAmdi AzIKIWE University, AWKa. ANAmbra State NiGERIA. \\ Email addresses: ${ }^{1}$ amuluchijioke@gmail.com, ${ }^{2}$ ac.ezeagu@unizik.edu.ng
}

\begin{abstract}
This study investigated the effect of combined actions of torsional moments, bending moments and shear forces in reinforced concrete beams with concrete compressive strength of $30 \mathrm{~N} / \mathrm{mm}^{2}$.The ultimate torsional moments, bending moments, and shear forces of the beams were determined experimentally, through a simple test arrangement set-up on fifteen beam specimens grouped from BC1 to BC5, three beam specimens in each group. The combined loads were induced by loading the test beams at an eccentricity of $65 \mathrm{~mm}$ from the beam's principal axis at the mid-span, using Computerized Universal Testing Machine TUE-C-100. BS 8110, Euro code 2 and ACI 318 were used to calculate the ultimate torsional moments provided by both longitudinal and transverse reinforcements, bending moments and shear forces induced. The values obtained from the codes were compared with those of experimental results for validation. It was observed that Eurocode 2 predicted the highest bending moment of $21.1530 \mathrm{kNm}$, the highest torsional moments of $9.8470 \mathrm{kNm}$ and $12.6193 \mathrm{kNm}$, for torsional resistance provided by longitudinal and transverse reinforcements respectively, at an angle crack of $45^{\circ}$, while BS 8110 predicted the least values. ACI 318 predicted the highest value of internal shear forces that the beams possessed before yielding to the applied loads.
\end{abstract}

Key words: bending moment, shear force, torsional moment, codes, reinforcement

\section{INTRODUCTION}

In structural analysis and design, the effects of torsion are usually neglected and only bending, shear and axial forces are taken into consideration. This is because torsion was considered to be a secondary effect that will be covered in the factor of safety [1] or be taken care of by shear design. Less attention was paid in the past by reinforced concrete designers to these effects of torsion in reinforced concrete members. When torsion is encountered in reinforced concrete members, it usually occurs in combination with flexure and transverse shear. The interactive behaviour of torsion with bending moment and flexural shear in reinforced concrete beam is fairly complex, owing to non-homogeneous, non-linear and composite nature of the material and presence of cracks [2].

On several situations, beams and slabs are subjected to torsion in addition to bending moment and shear force. Combined torsional moment, bending moment and shear force may be induced in a reinforced concrete beam in various ways during the process of load transfer in a structural system. When a beam is subjected to transverse loading such that the resultant force passes through the longitudinal shear axis, the beam will not twist, but bends. However, when the resultant force acts away from the shear center axis, moment is induced into the system [3]. This moment causes a body to rotate and if the structural system tries to resist such rotational tendency, bending and /or torsion results [4]. This implies that if applied loads are "eccentric" from the centroid and the resultant forces do not pass through the member's centroid, then torsion occurs [5]. It is therefore imperative to take into cognizance the combined effect of torsion, bending and shear stresses while designing members subjected to these forces.

There are well established procedures for dimensioning reinforced concrete beams subjected to axial load or moment, or combined axial load and moment. These procedures are based on rational, simple, general design models which can be embodied in a few paragraphs of code or specification documents. Such failure models provide the designer with means to evaluate the ultimate moment capacity of quite irregular sections in reinforced concrete. The same basic models, in addition can be used 
to study the interaction between axial load and moment, making the related design process relatively simple and straightforward.

However, design provisions in codes in the areas of combined torsion, bending and shear stresses are not of the same level of rationality and general applicability. The absence of rational models has resulted in highly empirical design procedures characterized by large differences in values evaluated from different design codes when compared to experimental test results.

Structural members curved in plan, members of a space frame, eccentrically loaded beams, inverted L-beams as in supporting sunshades and canopies, curved box girders in bridges, edged beams of slabs or spandrel beams in buildings and spiral stair-cases are typical examples of structural elements subjected to combined torsion, bending and shear stresses and their effect cannot be neglected while designing such members $[6$, 7].

This paper investigates the effects of combined torsional moment, bending moment and shear force induced in reinforced concrete beams at a given compressive strength of concrete. It examines the design procedures for torsion, bending and shear in BS 8110, Euro code 2, and ACI 318 building code; evaluates the torsional, bending and shear stresses induced in reinforced concrete beams subjected to combined actions of shear, bending and torsion, using these codes and experimental work; and validates the provisions of the codes by comparing the calculated code values with experimental results.

However, design provisions in the areas of combined torsion, bending and shear stresses are not of the same level of rationality and general applicability. The absence of rational models has resulted in highly empirical design procedures characterized by large difference in values evaluated from different design codes when compared to experimental test results.

Aim of the Study: To determine the effects of combined torsional moment, bending moment and shear force induced in reinforced concrete beams at a given compressive strength.

Objectives of Study: The objectives of this study include:

1) To examine and compare the torsional, bending and shear design procedures in BS 8110, Euro code 2, and ACI 318 building code.

2) To evaluate the torsional stresses, bending stresses and shear stresses induced in reinforced concrete beams subjected to combined actions of shear, bending and torsion using standard design codes and experimental work.
3) To validate the provisions of the codes by comparing the calculated design code values with that of experimental results.

\section{PROVISIONS FOR CURRENT STRUCTURAL STANDARD CODES OF PRACTICE FOR SHEAR, TORSION AND BENDING}

\subsection{ACI building code Provision (ACI 318)}

The first provision for torsion appeared in ACI 318-63 [8]. It consisted of one sentence, which prescribed the use of closed stirrups in edge and spandrel beams and one longitudinal bar in each corner of those closed stirrups. Comprehensive design provisions for torsion were introduced through a series of papers by ACI committee 438, in 1968 and 1969 and later adopted in the 1971 ACI Building code. These design requirements remained essentially unchanged through the 1989 and 1992 provisions [1] and [9]. The method of design for torsion and for combined torsion, shear and flexure in beams were revised in the ACI 318-95 Code of 1995 and remain essentially unchanged since then. This design procedure for solid and hollow members is based on a thin-walled tube, space truss analogy.

The basic truss equation relating the torsional strength to the quantity of longitudinal reinforcement is

$$
T_{n}=2 A_{o} \frac{A_{l} f_{y l}}{P_{h}} \tan \theta
$$

The basic truss equation relating the torsional strength to quantity of hoop reinforcement is

$$
T_{n}=2 A_{o} \frac{A_{t} f_{y v}}{S} \operatorname{Cot} \theta
$$

Where: $A_{o}$ is the gross area enclosed by perimeter of the wall within the shear flow path, $P_{h}$ is the outside perimeter of concrete cross section, $A_{l}$ is cross sectional and of longitudinal bars, $A_{t}$ is the cross sectional area in one leg of stirrup bars, $f_{y l}$ is the yield strength of longitudinal bars, fyv is the yield strength of transverse bars, $\theta$ is the angle of inclination, and $\mathrm{s}$ is the spacing of links

The ACI provisions permit $A_{o}$ to be taken as $0.85 A_{o h}$. Section 11.6.3.6 of the ACI Code states that the angle of inclination $\theta$ of the compression diagonals "shall not be taken smaller than 30 degrees." but then goes on to suggest that $\theta$ be taken equal to 45 degrees for non-pre stressed members and 37.5 degrees for pre stressed members. The code allows any value between 30 and 60 degrees (ACI 11.5.3.6).The commentaries suggest that $\theta$ can be obtained by analysis [10].

\subsection{Euro Code Provision}

The EC2 equations for torsional design are developed from a structural model where it is assumed that the concrete beam in torsion behaves in a similar fashion to a 
thin-walled box section. The box is reinforced with longitudinal bars in each corner with closed loop stirrups as transverse tension ties and the concrete providing diagonal compression struts [11]. Euro code 2 gives the principles and some limited design equations for a generalized shape of a hollow box section.

The basic truss equation relating the torsional strength to the quantity of longitudinal reinforcement is

$$
T_{R d 1}=2 A_{k} \frac{A_{s l} f_{y l}}{U_{k}} \tan \theta
$$

The basic truss equation relating the torsional strength to quantity of hoop reinforcement is

$$
T_{R d 2}=2 A_{k}\left(\frac{A_{s w}}{S}\right) f_{y t} \operatorname{Cot} \theta
$$

Where: $A_{k}$ is the area enclosed with in the centre line of the hollow box section, $s$ is the spacing of links, $A_{g w}$ is the cross section area of links, $A_{g l}$ is the area of longitudinal bars, fyt is yield strength of transverse bars, $f_{y l}$ is yield strength of longitudinal bars and $\theta$ is the angle of inclination.

There are practical limitations on the values of $\theta$ that can be used and EC2 recommends that $1.0 \leq \operatorname{Cot} \theta \leq 2.5$ representing limiting values of $\theta$ to $45^{\circ}$ and $22^{\circ}$ respectively, but can be taken as $\theta=45^{\circ}$.

\subsection{British Standard (BS 8110)}

If a section is subjected to bending moment $M$, shear force $\mathrm{V}$, and torsion $\mathrm{T}$, it is necessary to design the transverse and longitudinal steel. It should be separately designed for shear force, bending moment and torsion. In typical framed construction, specific consideration of torsion is not usually required where torsional cracking is adequately controlled by shear reinforcement.

If the design relies on the torsional resistance of a beam, further consideration should be given using the following sections (BS 8110-2:85 3.4.5.13).

The torsional resistance of all links crossing the cracks is calculated as:

$$
\frac{A_{s v, t}}{S_{v}}=\frac{T}{0.8 x_{1} y_{1}\left(0.87 f_{y v}\right)}
$$

And the required longitudinal reinforcement, is calculated from

$$
A_{l}=\frac{A_{s v, t} f_{y v}\left(x_{1}+y_{1}\right)}{S_{v} f_{y}}
$$

Rearranging Equation (6), the torsional moment provided by longitudinal reinforcement is determined as:

$$
T_{U S 1}=\frac{A_{l}\left(0.8 x_{1} y_{1}\right)\left(0.87 f_{y l}\right)}{\left(x_{1}+y_{1}\right)}
$$

The angle of cracks is fixed at $\theta=45^{0}$

Where, $x_{1}$ and $y_{1}$ is the length of arms of stirrups, $s_{V}$ is spacing of links, $A_{s V}$, is the cross sectional area of links, $A_{I}$ is area of longitudinal bars, $f_{y V}$ is yield strength of transverse bars, $f_{y l}=$ yield strength of longitudinal bars,

\section{MATERIALS AND METHOD}

\subsection{Materials}

The concrete beam specimens were cast to attain 28-day concrete cube strength of about30MPa, with design mix ratio of cement, fine and coarse aggregates of $1: 1.5: 3$, batched by volume, water/cement ratio of 0.52 . The concrete was placed in two layers, each layer being deposited continuously around the beam formwork and uniformly tamped with a steel rod. The top surface of concrete is struck with a wooden float and neatly finished with a steel trowel. The arrangements of reinforcement in beam specimens are grouped into five as detailed in Table 1.The beam specimens have the same cross-section of $150 * 150 * 1500 \mathrm{~mm}$, with beams marked $\mathrm{BC} 2, \mathrm{BC} 3, \mathrm{BC} 4$ and $\mathrm{BC} 5$ reinforced longitudinally and transversely with varying number of bars and spacing of stirrups. While beam marked BC1 has no reinforcement. The cast beam specimens were cured using wet burlap sack to cover and water being sprinkle on it at least twice a day while the concrete cubes were wholly immersed in water tank for the 28 days.

\subsection{Method}

The confirmatory tests carried out in this study include; sieve analysis of fine and course aggregates, uniaxial tensile strength of reinforcement bars, and slump test of wet concrete, the compressive strength of concrete cubes at 7 and 28 days respectively, the combined actions of bending moment, torsional moment and shear force test (loaded at an eccentricity of $65 \mathrm{~mm}$ from the shear centre axis at mid-span of the beam specimens).

The methodology used in this study was based on experimental design of fifteen rectangular reinforced concrete beams. Each beam specimen was loaded eccentrically from its principal axis by a combined action of bending, shear and torsional load, applied through a system of Computerized Universal Testing machine TUEC-100. The experimental results were compared with design provisions of three international standard codes namely: BS 8110, Euro Code 2 and ACI 318 building code. Choice of test assembles: The objective of the design of rectangular beam was to provide a simplified test arrangement and to ensure a failure of the test beams in combined actions of bending, shear and torsion without causing a failure in other elements. The test beams were seated on two steel supports resting on the laboratory floor. The test beam is simply supported but restricted at both ends on the steel support in other to avoid rotation, then could be loaded at any desired eccentricity from the beam principal axis, through a system of Computerized Universal Testing machine TUE-C-100 with a pointloading head. 
Five groups of specimens, each group contains three $150 * 150 * 1500 \mathrm{~mm}$ long rectangular reinforced concretewere cast. All the samples have effective span of $1200 \mathrm{~mm}$. The beams were designed for stresses of $30 \mathrm{~N} / \mathrm{mm}^{2}$ in concrete and $460 \mathrm{~N} / \mathrm{mm}^{2}$ in reinforcement. The designed test beam specimens are to carry a maximum uniform distributed load of $25 \mathrm{kN} / \mathrm{m}$ at an eccentricity of $65 \mathrm{~mm}$, required $8 \mathrm{~mm}$ diameter of stirrups at $150 \mathrm{~mm}$ centre to center and $10 \mathrm{~mm}$ diameter of longitudinal reinforcement to resist calculated shear and torsion. However, the spacing of the stirrups was varied for the test beam specimens to study the effect of transverse reinforcement on the ultimate strength of the test beam. Number of bars provided as longitudinal reinforcement was also varied to determine its effect on torsional capacity of the beams tested. The choice of $8 \mathrm{~mm}$ diameter bars for transverse reinforcements, $10 \mathrm{~mm}$ diameter bars for longitudinal reinforcements and compressive strength of $30 \mathrm{~N} / \mathrm{mm}^{2}$ for concrete was to ensure that load capacity of the Computerized Universal Testing Machine TUE-C-100 was not exceeded. Hence, to ensure that the beam specimens failed before the maximum load capacity of the machine is reached, $8 \mathrm{~mm}$ and $10 \mathrm{~mm}$ diameter bars were selected in the experimental work.

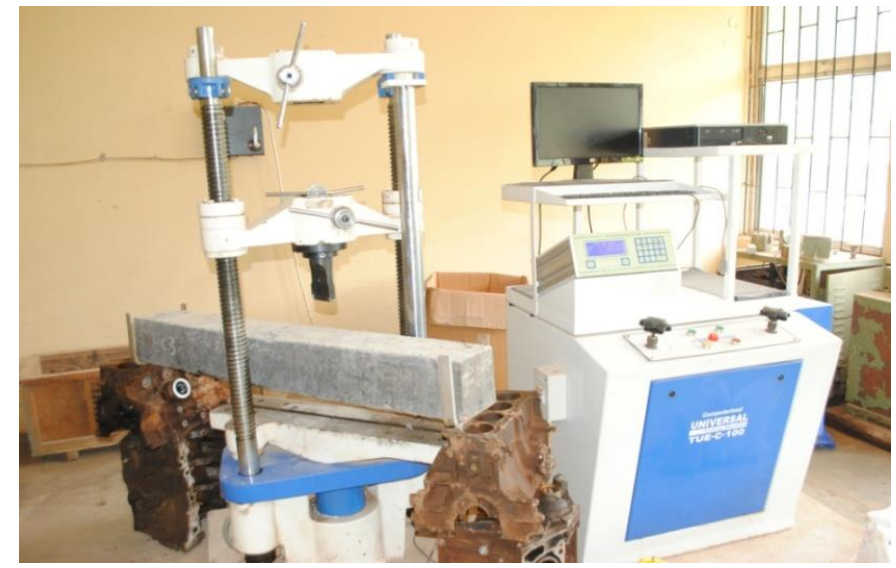

Figure 1: Experimental Set-up

\section{RESULTS AND DISCUSSION}

To validate the experimental results, the three standard design codes, BS 8110, Euro Code 2 and ACI 318, were used to design the beams and their values tabulated for comparison. The values determined for comparison include: the torsional moments predicted by the codes for torsional resistance provided by both transverse and longitudinal reinforcements, bending moments and shear forces.

Table 1: Summary of characteristics of Reinforced Concrete Beams Tested (all the samples are $150 * 150 * 1500 \mathrm{~mm}$ long and compressive strength of $30 \mathrm{~N} / \mathrm{mm}^{2}$ ).

\begin{tabular}{|c|c|c|c|c|c|c|}
\hline $\begin{array}{c}\text { Beam } \\
\text { notation }\end{array}$ & $\begin{array}{c}\text { Longitudinal } \\
\text { bars (mm) }\end{array}$ & $\begin{array}{c}\text { Areas of } \\
\text { longitudinal bars } \\
\left(\mathrm{mm}^{2}\right)\end{array}$ & $\begin{array}{c}\text { Stirrups } \\
\text { bars (mm) }\end{array}$ & $\begin{array}{c}\text { Spacing of } \\
\text { links (mm) }\end{array}$ & $\begin{array}{c}\text { Areas of } \\
\text { transverse bars } \\
\left(\mathrm{mm}^{2} / \mathrm{mm}\right)\end{array}$ & $\begin{array}{c}\text { Eccentricity of } \\
\text { loading (mm) }\end{array}$ \\
\hline BC1 & \multicolumn{6}{|c|}{ Not reinforced } \\
\hline BC2 & $4 \mathrm{~T} 10$ & 314 & R8 & 200 & 0.503 & 65 \\
\hline BC3 & $4 \mathrm{~T} 10$ & 314 & R8 & 100 & 1.006 & 65 \\
\hline BC4 & $6 \mathrm{~T} 10$ & 471 & R10 & 200 & 0.503 & 65 \\
\hline BC5 & 6 6T10 & 471 & R10 & 100 & 1.006 & 65 \\
\hline
\end{tabular}

Table 2: Bending moments predicted by the Codes and experimental result.

\begin{tabular}{ccccc}
\hline \multirow{2}{*}{$\begin{array}{c}\text { Beam } \\
\text { sample }\end{array}$} & $\begin{array}{c}\text { BS } \\
\text { 8110 }\end{array}$ & $\begin{array}{c}\text { Euro } \\
\text { Code 2 }\end{array}$ & ACI 318 & $\begin{array}{c}\text { Experimental } \\
\text { Result }\end{array}$ \\
\cline { 2 - 5 } & $(\mathrm{kNm})$ & $(\mathrm{kNm})$ & $(\mathrm{kNm})$ & $(\mathrm{kNm})$ \\
\hline BC1 & 3.34308 & 3.34308 & 3.34308 & 3.34308 \\
BC2 & 12.9470 & 14.1002 & 11.701 & 12.4416 \\
BC3 & 12.9470 & 14.1002 & 11.701 & 15.2066 \\
BC4 & 19.4198 & 21.1503 & 17.553 & 13.2526 \\
BC5 & 19.4198 & 21.1503 & 17.553 & 15.4451 \\
\hline
\end{tabular}

Table 3: Shear forces predicted by the Codes and experimental result.

\begin{tabular}{ccccc}
\hline \multirow{2}{*}{$\begin{array}{c}\text { Beam } \\
\text { sample }\end{array}$} & \begin{tabular}{c} 
BS \\
\cline { 2 - 5 }
\end{tabular} & $\begin{array}{c}\text { Euro } \\
\text { Code 2 }\end{array}$ & ACI 318 & $\begin{array}{c}\text { Experimental } \\
\text { Result }\end{array}$ \\
\hline BC1 & 5.772 & $(\mathrm{kN})$ & $(\mathrm{kN})$ & $(\mathrm{kN})$ \\
$\mathrm{BC} 2$ & 13.2601 & 21.775 & 5.772 & 5.772 \\
$\mathrm{BC} 3$ & 26.5201 & 43.5497 & 47.1231 & 25.4045 \\
$\mathrm{BC} 4$ & 13.2601 & 21.775 & 23.562 & 22.3145 \\
$\mathrm{BC} 5$ & 26.5201 & 43.5497 & 47.1231 & 25.9686 \\
\hline
\end{tabular}


Table 4: Torsional moments predicted by the Codes for torsional resistance provided by longitudinal reinforcement at angle of crack, $\theta=45^{\circ}$ and experimental result.

\begin{tabular}{|c|c|c|c|c|}
\hline \multirow{2}{*}{$\begin{array}{l}\text { Beam } \\
\text { sample }\end{array}$} & $\begin{array}{c}\text { BS } \\
8110 \\
\end{array}$ & $\begin{array}{l}\text { Euro } \\
\text { Code } 2 \\
\end{array}$ & $\begin{array}{l}\text { ACI } \\
318 \\
\end{array}$ & $\begin{array}{c}\text { Experimental } \\
\text { Result } \\
\end{array}$ \\
\hline & $(\mathrm{kNm})$ & $(\mathrm{kNm})$ & $(\mathrm{kNm})$ & $(\mathrm{kNm})$ \\
\hline BC1 & - & - & - & 0.6914 \\
\hline BC2 & 5.0265 & 6.5647 & 5.6097 & 2.6662 \\
\hline BC3 & 7.5398 & 6.5647 & 5.6097 & 3.2436 \\
\hline BC4 & 5.0265 & 9.8470 & 8.4151 & 2.8419 \\
\hline BC5 & 7.5398 & 9.8470 & 8.4151 & 3.31695 \\
\hline
\end{tabular}

Table 5:Torsional moments predicted by the Codes for torsional resistance provided by transverse reinforcement at angle of crack, $\theta=45^{\circ}$ and experimental result.

\begin{tabular}{ccccc}
\hline \multirow{2}{*}{$\begin{array}{c}\text { Beam } \\
\text { sample }\end{array}$} & \begin{tabular}{c} 
BS \\
\cline { 2 - 5 }
\end{tabular} & $\begin{array}{c}\text { Euro } \\
\text { Code } 2\end{array}$ & $\begin{array}{c}\text { ACI } \\
318\end{array}$ & $\begin{array}{c}\text { Experimental } \\
\text { Result }\end{array}$ \\
\hline BC1 & - & $(k N m)$ & $(k N m)$ & $(k N m)$ \\
BC2 & 1.6104 & 6.3096 & 3.652 & 2.6662 \\
BC3 & 3.2208 & 12.6193 & 7.3047 & 3.2436 \\
BC4 & 1.6164 & 6.3096 & 3.652 & 2.8419 \\
BC5 & 3.2208 & 12.6193 & 7.3047 & 3.31695 \\
\hline
\end{tabular}

Calculations on how the ultimate torsional resistances provided by longitudinal and transverse reinforcements were calculated using BS 8110, Euro Code 2 and ACI 318 code. Refer to Table 1 for other parameters.

ACI 318:

$$
\begin{gathered}
\theta=45^{\circ} ; f_{c}^{\prime}=4000 p s ; f_{y}=60000 p s i ; \\
A_{c p}=6 * 6=36 i^{2}, P_{h}=2_{y o}+2_{x o}=2 \times 4+2 \times 4 \\
=16 i n
\end{gathered}
$$

BC 5: $\quad T_{A C I, A l}=2 \times \frac{13.6 \times 0.7301 \times 60 \times 1}{16}=74.4702 \mathrm{in}-$ kips $(8.4151 \mathrm{kNm} S I U)$

$T_{A C I, A t}=2 \times 13.6 \times 0.03961 \times 60 \times 1$

$$
=64.6435 \mathrm{in}-\mathrm{kips}(7.3047 \mathrm{kNm} \text { SIU) }
$$

Euro Code 2:

$\boldsymbol{\theta}=\mathbf{4 5}^{\boldsymbol{o}}, f_{y z}=500 \mathrm{~N} / \mathrm{mm}^{2}, f_{c k}=30 \mathrm{~N} / \mathrm{mm}^{2}$

$$
A_{k}=(150-38)(150-38)=12544 \mathrm{~mm}
$$

BC 2: $T_{E C 2, A L}=500 \times\left(\frac{314}{600}\right) \times 2 \times 12544 \times 1 \times 10^{-6}=$ $6.5647 \mathrm{kNm}$

$$
\begin{gathered}
T_{E C 2, A t}=500 \times(0.503) \times 2 \times 12544 \times 1 \times 10^{-6} \\
=6.3096 \mathrm{kNm}
\end{gathered}
$$

BC 5: $T_{E C 2, A L}=500 \times\left(\frac{471}{600}\right) \times 2 \times 12544 \times 1 \times 10^{-6}=$ $9.8470 \mathrm{kNm}$

$$
\begin{gathered}
T_{E C 2, A t}=500 \times(1.006) \times 2 \times 12544 \times 1 \times 10^{-6} \\
=12.6193 \mathrm{kNm}
\end{gathered}
$$

BS 8110:

$$
\begin{gathered}
f_{c u}=30 \mathrm{~N} / \mathrm{mm}^{2}, f_{y}=460 \mathrm{~N} / \mathrm{mm}^{2}, d=111 \mathrm{~mm}, f_{y v} \\
=250 \mathrm{~N} / \mathrm{mm}^{2} \\
y_{1}=150-2 \times 25=100 \mathrm{~mm}, x_{1}=150-2 \times 25 \\
=100 \mathrm{~mm}
\end{gathered}
$$

BC 2: $T_{B S, A L}=0.503 \times(0.8 \times 100 \times 100)(0.87 \times 460) \times$ $10^{-6}=1.6104 \mathrm{kNm}$

$$
\begin{gathered}
T_{B S, A t}=\frac{314 \times(0.8 \times 100 \times 100)(0.87 \times 460)}{(100+100)} \times 10^{-6} \\
=5.0265 \mathrm{kNm} \\
T_{B S, \text { Conc }}=\frac{1}{2} \times 0.2 \sqrt{30} \times 150^{2} \times\left(150-\frac{150}{3}\right) \times 10^{-6} \\
=1.2324 \mathrm{kNm}
\end{gathered}
$$

BC 5: $T_{B S, A L}=1.006 \times(0.8 \times 100 \times 100)(0.87 \times 460) \times$ $10^{-6}=3.2208 \mathrm{kNm}$

$$
\begin{aligned}
T_{B S, A t}=\frac{471 \times(}{} & =.8 \times 100 \times 100)(0.87 \times 460) \\
= & 7.5398 \mathrm{kNm}
\end{aligned}
$$

Table 2 presents the bending moments predicted by the codes and experimental results. From this table, it was clear that values predicted by the codes matched with each other in analytical and experimental results for the control beam, BC1. But for other beams, the predictions of the codes differ, both analytically and experimentally. For instance, Euro code 2 predicted the highest value of internal ultimate bending moment that the tested beams possessed before failure/yielding occurred, while ACI 318 predicted the least value. This is evident from the table where, for beam group BC5, Euro code's value was $21.1503 \mathrm{kNm}$, BS 8110 value, $19.4198 \mathrm{kNm}$, and ACI 318 value, $17.553 \mathrm{kNm}$, while the experimental result was $15.4451 \mathrm{kNm}$. While ACI 318 predicted the least value $17.553 \mathrm{kNm}$. However, when the values were subjected to ANOVA Test at $5 \%$ level of significance, there was a significant difference statistically ( $F_{\text {critical }}(3.2388)>$ $F_{\text {calculated }}(0.11)$.From this table, beams are said to have failed/ yielded by bending moment if values observed from experiment are greater than calculated values predicted by each code. This implies that beams in ACI 318 yielded/ failed in group beams BC2 and BC3; only beam group BC3 failed/ yielded in Euro code 2 while in BS 8110, beam group BC3 failed/ yielded.

Table 3 presents the shear forces predicted by the codes and experimental result. From this table, ACI 318 predicted the highest shear force that the tested beams possessed to resist the applied loads, while BS 8110 gave the least value. From beam group BC3, ACI 318 value is $47.1231 \mathrm{kN}$, Euro code 2 value is $43.5497 \mathrm{kN}$ while BS 8110 value is $26.5201 \mathrm{kN}$. A beam is said to fail/ yield in 
shear force if the value obtained experimentally is greater than that predicted by the codes. Beam groups BC2 and BC4 failed/ yielded in BS 8110; BC3 did not fail/yield in Euro code 2; while none of the beam groups failed/ yielded in ACI 318.

Table4 presents the ultimate torsional moments predicted by codes for torsional resistance provided by longitudinal reinforcement at $\theta=45^{\circ}$. From the table, Euro code 2 predicted the highest value of torsional moment followed by ACI318 while BS 8110 predicted the least value. In other words, in beam group BC4, Euro code 2 value is $9.847 \mathrm{kNm}$, ACI 318 value is $8.4154 \mathrm{kNm}$ while BS 8110 value is $5.0265 \mathrm{kNm}$. In this case, a beam is said to fail/ yield if the torsional moment observed from experiment is greater than that predicted by codes. This implies that none of the beams predicted by the three codes failed/ yielded in longitudinal reinforcement due to torsion, because values calculated from codes are greater than experimental results in longitudinal reinforcement resistance to torsion.

Table 5 presents the ultimate torsional moments predicted by codes for torsional resistance provided by transverse reinforcement at $\theta=45^{\circ}$. From the table, Euro code 2 predicted the highest value of torsional moment of $12.6193 \mathrm{kNm}$ in beam group BC5, followed by ACI 318, with a value of $7.3047 \mathrm{kNm}$, while BS 8110 predicted the least value of $3.31659 \mathrm{kNm}$. In this case, a beam is said to fail/yield if the torsional moment observed from experiment is greater than that predicted by codes. This implies that none of the beams predicted by Euro code 2 and ACI 318 code failed/yielded in transverse reinforcement due to torsion, while all the beams predicted by BS 8110 yielded in transverse reinforcement. From all the tables presented, there is increase in beam's capacity to resist effect of the applied combined loads. In other words, as the areas of longitudinal reinforcement increases, together with a reduction in the spacing of the transverse reinforcement down the group, the higher the strength of the beams' capacity to resist the applied loads. This indicates the need to provide torsional reinforcements together with those calculated for bending moment and shear force design as their interaction increases the capacity of the beams to resist yielding/ failure.

\section{CONCLUSION AND RECOMMENDATION}

The experimental result indicated that the codes studied were able to predict quite conservative and consistent values of the internal ultimate torsional moments, bending moments and shear forces induced in beams subjected to combined torsion, bending and shear force. Hence, this study concludes that Euro code 2 gave the highest internal ultimate bending moment and torsional strengths for torsional resistance provided by both longitudinal and transverse reinforcements at $\theta=45^{\circ}$. ACI 318 predicted the highest internal shear forces that the beams possessed before yielding to the applied loads, while BS 8110 predicted the least values of bending moment, shear force and torsional resistance provided by both longitudinal and transverse reinforcements.

It can also be concluded from this study that the beams failed due to the combined actions of torsion, shear and bending moment effects. Therefore, increase in the capacity of the beams to resist the applied combined loads, were as a result of the increase in areas of both longitudinal and transverse reinforcements down the beam groups.

The study also concluded that the calculated amount of reinforcement obtained from torsional design must be provided in addition to the full bending and shear reinforcement at ultimate loads, as the interaction of torsion and shear force or torsion and bending or combination of the three loads led to provision of higher areas of longitudinal and transverse reinforcement. This increases the capacity of thebeams to resist the effects of combined loads.

The study recommends further research at optimizing the angles of cracks, dimensions of beam cross section and eccentricity of loading in other to determine its effects on capacity of beams to resist combined loads.

The research also recommends the inclusion of torsional design for beams that are subjected to its effects or in combined actions, as increase in reinforcement due to torsion in both longitudinal and transverse directions of the beam increases the capacity of such beam.

\section{REFERENCES}

[1] Kamara, M. E., and Rabbat, B. G.. Torsion Design of Structural Concrete Based on ACI 318-05. Professional Development Series . 2007.

[2] Pillai, S., and Menon, D. Reinforced Concrete Design (3rd ed.). New Delhi: Tata Mc Graw Hill,Education private Limited. 2009.

[3] Davison, B and Owens, G Steel Designers' Manual (6 ${ }^{\text {th }}$ ed). UK: Blackwell Publishing Ltd. 2005.

[4] Onounye, B., and Kane, K. Statics and Strenght of Materials for Architectural and Building Construction (third ed.). New Jarsey: Pearson Prentice Hall. 2007.

[5] Amulu. C. P, and Ezeagu, C. A. Combined Torsion, Bending and Shear Analysis in Reinforced Concrete Beams. International Journal of Advanced Trend in Technology, Management and Applied Science. 2(6), 2016.

[6] Panchacharam, S., and Belarbi, A. (2002, October). Torsional Behaviour of Reinforced Concrete 
BeamsStrengthened with FRP composites. FIB Congress . 2002,

[7] Kharagpur, I. Structural Analysis: Civil Engineering Course Material (Vol. (40 lesson) version 2CE), 2008.

[8] Ramirez, J. A., and Breen, J. E. Proposed Design Procedures For Shear And Torsion In Reinforced And Prestressed Concrete. Texas State Department of Highways and Public Transportation; Transportation Planning Division in cooperation with the U. S. Department of Transportation, Federal Highway Administration. Austin, Texas: Center for TransportationResearch The University of Texas at Austin. 1983.

[9] Rahman, S. M., and Ahmed, I. Torsional Design Aspects of ACI 318-89 and ACI 318-95 Building Codeswith Reference to BNBC. Journal of Civil Engineering, the Institute of Engineers, 27 (1). 1999.

[10] Rahal, K. N and Collins, M. P. Experimental Evaluation of ACI and AASHTO-LRFD
DesignProvisions for Combined Shear and Torsion. ACI Structural Journal, 100 ( 3), 277-282. 2003.

[11] Mosley, B., Bungey, J., and Hulse, R. Reinforced Concrete Design (sixth ed.). New York: Book Power withPalgrave Macmillian. 2007.

[12] ACI Committee 318, "Building Code Requirements for Structural Concrete (ACI 318-11) and Commentary," American Concrete Institute, Farmington Hills, Michigan, 2011, 503. 2011.

[13] BS 8110: Structural use of concrete; Part 1: Code of practice for design and construction, 1997; Part 2: Code of practice for special circumstances, 1985; Part 3: Design charts for singly reinforced beams, doubly reinforced beams and rectangular columns, 1985.

[14] European Standard. Eurocode 2. Design of concrete structures. EN 1992-1-1, Draft for stage 49, Commission of the European Communities, European Committee for Treatment of Torsion of Reinforced Concrete Beams In... 519 Standardization, 2002. 